\title{
Ritual Frame Indicating Expressions: An Interview with Juliane House and Dániel Z. Kádár
}

\author{
Rong Chen \\ Professor, English Department, California State University, San Bernardino, \\ USA \\ Professor, School of English Studies, Xi'an International Studies University, \\ Xi'an, China \\ RChen@csusb.edu
}

Juliane House

Professor Emerita, Department of Languages and Cultures, University of Hamburg, Hamburg, Germany

Distinguished Professor and Director of PhD Programme (Applied Linguistics), Hellenic American University, Athens, Greece julianehouse@fastmail.fm

\author{
Dániel Z. Kádár \\ Qihang Chair Professor and Director of Research Centre, Centre for \\ Pragmatics Research, Dalian University of Foreign Languages, Dalian, \\ Liaoning, China \\ Research Professor and Chair of Research Group, Hungarian Academy of \\ Sciences Momentum Interactional Rituals Research Group, Hungarian \\ Research Institute for Linguistics, Budapest, Hungary \\ dannier@dlufl.edu.cn
}

In this interview, the interviewer Rong Chen, who is Discussion Papers Editor of Contrastive Pragmatics, asked two editors of the Journal, Juliane House and Dániel Kádár, to explain in some detail the essence of their framework, which is dedicated to the contrastive pragmatic analysis of pragmatically important expressions.

Rong Chen: Your Ritual Frame Indicating Expressions (RFIE) Theory seems to have gained popularity in contrastive pragmatics. Would you say a few words about it? 
Juliane House: Our new theory - Ritual Frame Indicating Expressions (R FIEs) is actually part of a more comprehensive model which my colleague Dániel Kádár and myself present in our new book, Cross-cultural Pragmatics, to be published in 2021 by Cambridge University Press. In this book, we have proposed a complex framework for cross-cultural pragmatic analysis, and RFIEs represent the lowest analytic unit in this framework. RFIE is a concept that allows us to conduct a systematic contrastive pragmatic analysis of expressions, and these expressions are intimately interconnected with both speech acts and discourse in our larger framework.

Dániel Kádár: When Juliane and I started to work together on this model, we initially wondered how we could bring together speech acts and interactional ritual. Expressions provide a gateway to this inquiry. Due to my background in interactional ritual theory, I wanted to get involved in speech act theory because it reveals a great deal about interactional rituals. Initially, we contrastively examined seemingly simple expressions and their ritual pragmatic load. For example, we analysed the use of expressions such as qing 请 (please) and duibuqi 对不起 (sorry) in large corpora. Such Chinese expressions are not only anchored in the speech acts of Request and Apologise respectively, but they also indicate specific ritual contexts. Surprisingly, this relationship between expressions, speech acts and ritual contexts was found to be very different in other linguacultures we investigated.

Juliane House: Dániel, let me cut in here. To properly contextualise our joint framework, we need to look back, historically, to understand why having such a theory is of importance today. Just as Dániel said that he had no background in speech act theory before our collaboration, I myself had no background in interactional ritual theory. My part in this story began in 1989, when I wrote a paper on one particular expression which represented what we later chose to call Ritual Frame Indicating Expressions, namely, please. In that paper, which was part of a volume dedicated to the well-known Cross-cultural Speech Act Realisation Project, my basic thesis was that the expression please has really nothing to do with politeness - even though many people, both then and now, believe and continue to believe that please is a 'politeness marker'. However, as I tried to show in that paper, please indicates the speech act of Request. What I did not consider at the time is whether this finding holds for typologically distant linguacultures: initially I only studied the typologically close linguacultures of English and German. This is where Dániel's knowledge of Chinese and his academic background in interactional ritual came into the picture, and 
it marked the beginning of our RFIE theory, which aims to pin down linguacultural variation in the relationship between expressions, speech acts and politeness with the aid of interactional ritual theory.

Dániel Kádár: Yes, absolutely. And what Juliane brought to our collaboration is a rigorous, bottom-up and empirical way of looking at expressions, speech acts and their interface with politeness.

Juliane House: We have also used our joint research to challenge essentialist views of language and culture. We believe that looking into patterns of language use through RFIEs provides a fundamental way to capture culturally embedded patterns of language use. For example, our research has revealed that many expressions in Chinese and Japanese are what we call more 'speech actheavy' than their counterparts in English and German. Deploying pragmatic concepts, such as our 'speech act-heaviness', also allows us to disregard essentialist concepts, such as 'cultural values' in our contrastive pragmatic research.

Dániel Kádár: As part of our framework, our aim was to develop a systematic way to compare groups of increasingly more complex expressions, such as qing 请 (please), jingging 敬请 (respectfully ask), fanqing 烦请 (trouble you with asking) in China and please, if you please and could you please in English. Examining such clusters of expressions helped us to develop a replicable framework for RFIES.

Juliane House: It might be useful to explain exactly what we mean by 'speech act-heaviness', which is a central concept in our RFIE theory. What we mean by the notion of speech act-heaviness is, quite simply, that in certain linguacultures, such as the Chinese, RFIEs are so intimately tied to a particular speech act that such expressions can practically have no other pragmatic function. Although this may sound straightforward, for someone like myself who used to be unfamiliar with Chinese, this fact was a real eye-opener! What we found in our contrastive pragmatic research of German and English RFIE expressions versus their Chinese counterparts is that it is only in the Chinese linguaculture that RFIEs are speech act-heavy, which means they are inseparably attached to a particular speech act. In English and German this is not the case, which means that RFIEs in these linguacultures often fulfil many other functions as well. These other functions are defined as 'ancillary functions' in our theory. It goes without saying that speech act-heavy functions are ritual in scope, whereas ancillary functions are more ambiguous in this respect. 
Dániel Kádár: Let me hop on here. My own background in our joint venture also includes sociopragmatic research. Now let's consider why sociopragmatics is relevant to an essentially pragmalinguistic notion like RFIE. Sociopragmatic logic allows us to examine why, in many 'Western' linguacultures, one can use expressions like thank you in an ironic or sarcastic way, whereas in Chinese I have never heard xiexie 谢谢 used in such a manner. Juliane and I bump into this contrastive problem all the time. The answer to this question is that in many East Asian linguacultures, so-called 'politeness markers', which we define as RFIEs, have a more direct relationship with ritual politeness than is the case in 'Western' linguacultures.

Rong Chen: You have proposed RFIE theory as an alternative to discursive politeness theories. In your view, what are the main inadequacies of discursive politeness theories such that an alternative theory is needed?

Juliane House: It is not only that expressions have been understudied in politeness research, but also without bringing together expressions, speech acts and rituals in a rigorous contrastive framework, it is very difficult to systematically capture such phenomena. When one studies expressions, one simply cannot initially ascribe terms like 'politeness' and 'impoliteness' to them, because using these terms to describe the function of an expression or a speech act actually preempts what we want to establish only through our analysis. Let's revisit for a moment our work on the expressions please, sorry and so on. We would never say that these are items that are essentially polite. Rather, what we need to find out first is whether they are speech act-heavy or not, and then consider the implications of speech act-heaviness on the cross-cultural tendencies of the polite or impolite use of these expressions.

Dániel Kádár: It should be noted that there are other ideas in the field of politeness by which expressions can be studied, such as 'situation-bound utterances'. Basically, in such theories, one first identifies a situation and then the expressions that people generally use in this particular situation are studied. Also, there are many frame-related research schemes in which the researcher sets the scene and observes what language users do in that scene, including their use of expressions. What we have tried to do is radically different: in our world, we take two or more corpora and don't bother with situations first, but instead see what types of situations are indicated by the expressions in our corpora, that is, we measure the situational spread in which the expressions occur. As a next step, we consider issues such as the interactional ritual use of 
these expressions, their relationship to speech acts, their politeness load and so on. We feel that this is a more reliable way to rigorously compare language use across cultures.

Juliane House: What Dániel has just outlined basically implies that we approach our data rather 'innocently'. This means that we start by identifying the expressions in our corpora and then analyse what they do in certain situational contexts, that is, we do not start the other way around with either the situation or something else at the outset. The very term 'Ritual Frame Indicating Expression' indicates this quite clearly. You start with 'innocent' little words and see what comes out of your corpus search, which is basically a non-essentialist, bottom-up and data driven approach to the cross-cultural study of expressions. As far as I am aware, scholars have not proceeded in this way before in politeness research. The reason why we were able to look at language use in this alternative way is that we ventured beyond our respective 'comfort zones', that is, we brought together my original speech act and 'standard situation' approach and Dániel's interactional ritual theory.

Dániel Kádár: And just a quick addition. In my previous work on interactional ritual I argued that ritual overlaps a great deal with politeness, but, at the same time, ritual is a more complex phenomenon than politeness. What I find beautiful in our joint work is that it reveals that RFIEs - the lexical manifestations of ritual - have a particularly complex relationship with politeness. It is ironic that Juliane pointed out issues surrounding the ritual-politeness interface as early as 1989, and then it took me many years to realise that we cannot research interactional ritual and politeness without considering what Juliane had found many years earlier.

Rong Chen: Juliane just mentioned the concept of 'standard situation'. What are 'standard situations'? How do you define them and in what way are they important and relevant to interactional rituals?

Juliane House: Again, I have to refer back to my paper in the volume on the Cross-Cultural Speech Act Realization Project (CCSARP), where I compared the English and German expressions please and bitte in different contexts. Here, I came up with the notion of 'standard situation' which I borrowed from the work of a group of German cognitive experimental psychologists. These psychologists had conducted experiments involving participants who were asked to realise requests in various situations. These researchers found that there 
are certain situations in which the participants are more clearly aware of their rights and obligations than in others. In these situations, which they called 'standard situations', language use very often indicates that all interactants know exactly who and where they are. Consequently, ritual rules hold for these situations - although back in time I didn't consider Dániel's ritual - and thus it is only compulsory for the participants to conduct minimal facework in such contexts. So, in standard situations, certain otherwise non-licensed expressions become licensed. This means, for instance, that in the situation where a policeman admonishes a traffic offender, the policeman is perfectly within his rights to use a very direct raw imperative, such as Please move your car right now, which is not perceived as being impolite (or polite) because the policeman has the right to realise this very direct, ritually embedded request, and the driver of the car has the ritual obligation to immediately move his car. The expression please in this situation is not a 'politeness marker', as I mentioned previously, but is instead a requestive marker indicating the operation of an interactional ritual in which rights and obligations prevail. What was missing from my original theory is a framework of interactional ritual problematising the ritual-politeness interface, which Dániel brought to our collaboration.

Dániel Kádár: What I found amazing is that, back in the 1980s, CCSARP researchers and Willis Edmondson, Juliane's late husband, were actually heavy ritualists primarily because they had been influenced by Erving Goffman. Interestingly, these scholars had never considered themselves to be ritualists. Through my work with Juliane, I realised that their work was highly relevant to interactional ritual theory, even beyond the speech act-ritual interface. Unfortunately, the interactional ritual line of thinking adopted by Juliane, Willis and the CCSARP team has largely disappeared from pragmatics. I feel that a concept like standard situation is simply begging for a ritual analysis, and it provides an important, corpus-based way to capture interactional ritual in the Goffmanian sense.

Rong Chen: How did you proceed with your research into RFIEs?

Juliane House: When examining the use of RFIEs, we recognise the types of standard situations that these expressions actually indicate or evoke. Another important aspect is that before we actually start contrasting, for instance, Chinese, British or German RFIEs, we have to conduct detailed monolingual analyses of the individual forms in their respective linguacultures. This sequence is very important. We never start with a contrastive analysis - that is always the second step. 
Dániel Kádár: The procedure Juliane has just described also includes working closely with native speakers of each of the languages involved in the contrastive analysis of the RFIEs identified in our corpora. They help us to choose RFIEs that are actually compatible and contrastable: in our framework, we define the identification of RFIEs as the 'ancillary' part of our research.

Rong Chen: In what way is RFIE methodology 'bottom-up'? In your recent paper you argue that your framework is not to be used as a substitute for, but rather to complement, top-down sociopragmatic ritual research.

Juliane House: Maybe Dániel is the best person to answer this. As for myself, I don't really believe in the validity of studying any sociopragmatic phenomena, be it politeness or ritual, in an exclusively top-down manner. From what I have learnt from Dániel, interactional ritual theory affords both bottom-up and topdown approaches, with one complementing the other. In the study Rong has just mentioned, we display our model in a figure which explains that, while our approach is essentially bottom-up, it also provides the opportunity for a top-down take.

Dániel Kádár: Let me expand on the reasons why our framework is more bottom-up than top-down, although these two approaches are not in a contradiction. Conventional interactional ritual theory is typically top-down: ritualists have studied interactional ritual behaviour by preselecting and observing certain ritual contexts, such as public ceremonies, institutional interactions and so on. In a top-down pragmatic approach to interactional ritual, one looks at a particular situation like a dinner table conversation and examines the type of rituals in operation in that particular situation. But then there is the bottom-up complement to this, and that is how we proceed in our framework. Basically, in such an analysis we want to see how expressions and other pragmatic units, such as speech acts, indicate the ritual frame and the related expectations that underlie standard situations.

Rong Chen: What do you do with those RFIEs that exist in one language but not in another, such as honorifics in Japanese and Korean?

Juliane House: As a translation theorist, let me answer this question first. What one has to do in translation is to find equivalents to honorifics in those languages that do not have elaborate honorific systems, such as English and German. You have to find such pragmatic equivalents, instead of setting out on the impossible mission to find lexical equivalents. Regarding honorifics in 
Japanese or Korean, we have to ask ourselves how languages such as German and English compensate for the absence of proper honorifics.

Dániel Kádár: At the moment, Juliane and I are working on a major project which includes experts in Japanese. What needs to be resolved in a contrastive project involving honorifics is how to create a system that can bring together expressions in 'honorific-rich' and other linguacultures, and I feel that translation studies provides a gateway to this. We need to remember that we are not only talking about the expressions themselves, but also about the pragmatic systems behind such expressions. For example, in Classical Chinese there are thousands of self-denigrating expressions. We need to consider whether such a pragmatic system can be contrasted at all across linguacultures and, if it can be, then how.

Juliane House: Yes, in such research one always needs to look at how systems are put to use. This is why the notion of pragmatic equivalence is very important, not only in translation but also in contrastive pragmatics. What do I mean by 'pragmatic equivalence'? This notion - and I quote John Lyons here encompasses the application of a linguistic unit in a particular situation, and this we can contrast. In other words, one can never contrast pragmatic systems per se, but rather the use to which these systems are put.

Dániel Kádár: Funnily enough, even though we are only at the beginning of this project to contrastively study honorific-rich and other linguacultures, I feel that the outcome of such research might not always be positive. For instance, I am really looking forward to establishing what can definitely not be contrasted across linguacultures. Let me provide an example here from Chinese. In Chinese, when you talk about someone else's daughter you use the expression qianjin 千金 ('thousand golds'). You would never use this expression with respect to your own daughter. We really need to think carefully about what to do with such cases.

Rong Chen:The RFIE theory is proposed with contrastive pragmatics being the main field for its application. In pragmatics, contrastive studies have existed since the infancy of the field and many approaches have been adopted for contrastive purposes. One of the best-known approaches is contrasting how speech acts are realised cross-linguistically. Juliane is one of the forerunners in this area of research. So, what makes RFIE a superior approach to speech act analysis? What has caused Juliane, in particular, to 'jump ship'? 
Juliane House: No, I did not jump ship at all!

\section{Rong Chen: How so?}

Juliane House: Well, the RFIE approach is part of a bigger theory, as we have previously said. This theory integrates RFIEs with speech acts and discourse. So, for us, RFIE theory is only part of something bigger. When it comes to these expressions, my argument is that you cannot conduct proper speech act research without considering expressions, and this is particularly the case if contrastive cross-cultural pragmatics is at play. You also have to consider how expressions relate to speech acts, and how speech acts are, in turn, embedded in larger units of discourse. For instance, there is a straightforward relationship between expressions and speech acts in closing talk, opening talk, small talk, patch-up talk, remedial talk and so, and one cannot analyse such discourse phenomena without considering the expressions and speech acts that are frequently used in the realisation of these discursive phenomena, or the other way around. Basically, there is no contradiction between speech act theory and our new RFIE theory, and there is also no contradiction between RFIE theory and contrastive discourse analysis. They all belong together, although, of course, it is not only possible, but also sometimes necessary, to look at such various units individually.

Dániel Kádár: Let me contradict Juliane here: in a sense both of us have jumped ship, with Juliane coming to ritual, and myself turning to speech acts. However, I feel very strongly that locking ourselves into certain areas of research - like discourse analysis and speech act theory - is a form of self-deception.

\section{Acknowledgements}

We would like to thank Jiao Lin, Dalian University of Foreign Languages, for transcribing the interview.

In this interview, the participants referred to the following references:

Blum-Kulka, Shoshana, Juliane House, and Gabriele Kasper (eds.). 1989. Cross-Cultural Pragmatics: Requests and Apologies. Norwood, NJ: Ablex.

Hoppe-Graff, Siegfried, Theo Herrmann, Peter Winterhoff-Spurk, and Roland Mangold. 1985. Speech and situation: A general model for the process of speech production. 
In: Joseph P. Forgas (eds.), Language and Social Situations. New York: Springer, $81-95$.

House, Juliane. 1989. Politeness in English and German: The functions of please and bitte. In: Shoshana Blum-Kulka, Juliane House, and Gabriele Kasper (eds.), Cross-Cultural Pragmatics: Requests and Apologies. Norwood, NJ: Ablex, 96-119.

House, Juliane, and DánielZ. Kádár. 2021 (in press). Cross-CulturalPragmatics. Cambridge: Cambridge University Press.

Kádár, Dániel Z. 2017. Politeness, Impoliteness and Ritual: Maintaining the Moral Order in Interpersonal Interaction. Cambridge: Cambridge University Press.

Kádár, Dániel Z., and Juliane House. 2020. Ritual frames: A contrastive pragmatic approach. Pragmatics 30(1): 142-168.

Lyons, John. 1971. Theoretical Linguistics. Cambridge: Cambridge University Press. 